\title{
Iconografias de esquerda: encontro entre cultura visual e cultura política em fotografias da Guerra Civil Espanhola
}

\section{ERIKA ZERWES}

\section{Resumo}

Este artigo se volta para algumas fotografias realizadas por David Seymour "Chim” tematizando a Guerra Civil Espanhola, para analisar a construção de uma iconografia de cunho fortemente político. Pautado por causas da esquerda e do anti-fascismo, Chim lançou mão de um vocabulário imagético específico, que estava se formando naquele período, e que viria a impactar a cultura visual contemporânea, e em especial a fotografia documental.

Palavras-chave:

Fotojornalismo, fotografia de guerra, Guerra Civil Espanhola 


\section{Left wing iconographies: encounters between visual culture and political culture in Spanish civil War photographs}

\section{ERIKA ZERWES}

Keywords: Photojournalism, war photography, Spanish Civil War

\section{Abstract}

This paper focuses on some of David Seymour "Chim"'s photographs from the Spanish Civil War, to discuss the formation of a very political iconology. Driven by left and anti-fascist agendas, Chim reached for a specific imagetic vocabulary, which was being formed in that period and was going to cause an impact in contemporary visual culture, especially in documental photography. 
D avid Seymour "Chim" nasceu Dawid Szymin em Varsóvia, no ano de 1911. Deixou a Polônia para ir estudar na Alemanha em 1929, e em Paris em 1932. Já no ano seguinte tomou a iniciativa de se sustentar atuando como fotógrafo, uma vez que os negócios de sua família não iam bem devido às perseguições anti-semitas no país natal. Circulando entre os intelectuais e artistas de esquerda, muitos deles exilados, da capital francesa, em 1934 passou a trabalhar para a revista Regards sob o nome de Chim, modo com que soava em francês seu sobrenome.

A Regards havia aparecido pela primeira vez em Paris em 1924, com o título de Nos Regards: Illustré Mondiale du Travail. Nasceu como revista ilustrada semanal, uma iniciativa do Partido Comunista Francês, o PCF, que já havia lançado o jornal diário L'Humanité. Ela foi criada se espelhando na $A I Z$ (Arbeiter Illustrirte Zeitung - revista ilustrada dos trabalhadores) alemã, cujo proprietário, Willi Münzenberg, enviou a Paris dois membros do corpo editorial, Lily Corpus e Babette Gross, para auxiliarem na construção da revista francesa. Henri Barbusse e Máxime Gorki, que faziam parte da AIZ, vieram mais tarde se dedicar à Regards. No entanto, ela foi fechada em 1929 quando o governo de André Tardieu adotou uma política de repressão ao comunismo. Em janeiro de 1932 sua publicação foi retomada, agora sob o nome de Regards sur le Monde du Travail, mas sofrendo algumas mudanças: se tornou quinzenal em janeiro, e mudou seu nome para apenas Regards em setembro. Em janeiro de 1934 se tornou semanal, e a partir de 1935 passou a ser dirigida por Léon Mussinac e a ter como editor-chefe Pierre Unik.

A revista se desenvolveu no mesmo período da mudança de orientação do PCF que levou à integração de intelectuais e simpatizantes, antes hostilizados como burgueses. Ela era dirigida a uma classe social específica, pois tinha como 
objetivo mobilizar a classe trabalhadora em nome da construção de uma nova cultura proletária'. Ainda que fosse uma revista ilustrada, queria se afirmar a partir de uma clara distinção frente a imprensa burguesa. Optando por uma linguagem que se baseava na imagem, a revista buscava utilizar a fotografia como modo de alcançar este público, já acostumado a receber informações através de revistas ilustradas e do cinema. A classe trabalhadora compunha a maior parte das reportagens publicadas. Nesta revista, segundo Françoise Denoyelle (In BAQUÉ (ed), 1993, p. 311), o próprio estatuto da imagem fotográfica sofria uma modificação, pois a ela interessaria menos apresentar documentos com a pretensão de objetividade, do que usar a fotografia como um instrumento de combate e propaganda, como arma na luta de classes em favor dos trabalhadores. A autora (In BAQUÉ (ed), 1993, p. 313) ainda completa que, na revista,

La photographie se voit définie comme arme, comme support de la lutte concrète, (...) l'image n'est que l'indispensable mais non suffisante condition de possibilité d'une action encore à venir. Action dont l'entière responsabilité incombe au lecteur, et qui se donne pour horizon le combat libérateur, révolutionnaire.

Após a entrada de Mussinac e Unik na revista, ela se voltou para assuntos mais cotidianos, com o objetivo de concorrer com outras revistas ilustradas, em especial com a também francesa $V u$. A Regards se aproximou, assim, da concepção visual daquela revista para utilizar suas fotografias militantes, mas intentando manter sua contraposição àquela, vista como de posição sócio-democrata. Esta nova orientação a faria ganhar um maior público, aumentando seu tamanho em 1936, primeiro ano da Guerra Civil Espanhola, de 16 para 24 páginas, e alcançando uma tiragem de 100.0oo exemplares (DELL, In YOUNG, 2010, vol.1 p. 43; MOREL, 1999, pp. 18-19; MOREL, 2000, p. 18).

Chim já era contratado da Regards como colaborador em tempo integral desde a primavera de 1934. Quando militares que se auto-denominavam nacionalistas se rebelaram contra o governo republicano, na madrugada do dia 17 para 18 de julho de 1936, dando início aos conflitos, ele estava naquele país. O fotógrafo havia sido enviado pela Regards junto com o escritor Georges Soria para uma série de reportagens sobre o novo governo de Frente Popular, eleito a menos de um ano. Naquela madrugada eles estavam em Barcelona para cobrir as 
Olimpíadas dos Trabalhadores, organizada em paralelo aos Jogos Olímpicos de Berlim pelas esquerdas, em repúdio à sede do evento oficial estar sob um governo nazista. Com o golpe liderado por Franco em curso, ele então passou imediatamente a cobrir a sublevação militar e as decorrências - a guerra civil - para a revista, onde teve suas principais reportagens fotográficas publicadas - cerca de vinte e cinco. Suas fotografias desta guerra apareceram também, entre outros jornais e revistas, nos franceses Ce Soir, Vu, Match, no inglês News of Spain e na norte-americana Life (FONTAINE, 2003, p. 158; NAGGAR, 2011, s/p).

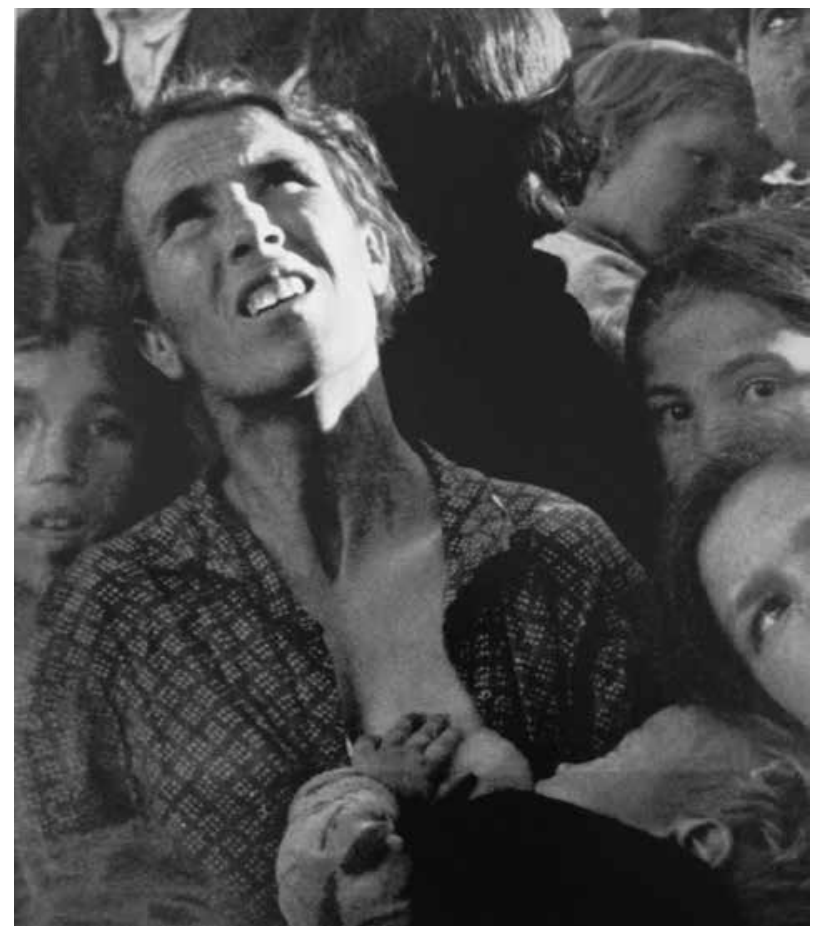

Uma das fotografias de Chim que se tornou mais emblemática da guerra espanhola foi a figura 1, que mostra uma mulher olhando para cima, enquanto amamenta uma criança em seu colo. Ao focar-se nas expressões de alguns dos rostos da multidão, em especial na mulher que carrega a criança e que se transforma em uma madona cristã rodeada por pequenos puti, a fotografia de Chim pôde simbolizar o grande sofrimento que a guerra trouxe à população espanhola frente a um conflito que não respeitou delimitações de frentes de batalha,
Figura 1

David Seymour "Chim". Mulher em reunião sobre divisão de terras. Estremadura, Espanha, abril ou maio de 1936. 
atacando igualmente combatentes e não combatentes. No entanto, este conjunto de significados foi ganho a posteriori. Ela é um reenquadre de uma imagem mais aberta, e foi realizada antes do início da guerra, quando Chim ainda estava fotografando aspectos da vida espanhola sob o governo da Frente Popular para a Regards. Esta fotografia retrata uma reunião em Estremadura feita em abril ou maio de 1936 pelo governo republicano sobre uma divisão de terras que este estava promovendo, portanto dois meses anterior à guerra. Quando o conjunto de negativos do período, conhecido como a Mala Mexicana (YOUNG, 2010, vol. 2 p. 17), foi recuperado em 2007, o negativo original desta imagem, que estava perdido desde o fim da guerra espanhola em 1939, mostrou que o fotógrafo a havia feito mais aberta, e que ela foi reenquadrada para ser publicada (figura 2). O reenquadre aproximou o rosto da mulher com a criança, deixando de fora o restante da multidão, uma grande quantidade de cabeças, que termina - fazendo como que uma linha do horizonte - em uma parede branca. Este reenquadre chamou portanto a atenção para a expressão da mulher que, assim como duas das quatro crianças que estão ao seu lado, olha para cima, provavelmente porque o orador da reunião está posicionado mais acima do que a multidão que o escuta.

Com o desenrolar da guerra, esta imagem passou a ter outro significado, uma vez que o lado do General Franco, com auxílio de aviões alemães, adotou a prática até então inédita do bombardeio aéreo não só a alvos militares, mas também a civis, e que teve um de seus auges no ataque que destruiu a cidade de Guernica em 26 de abril de $1937^{2}$. Assim, na Regards de maio de 1936, a imagem original foi publicada ao lado de outras fotografias desta reunião a céu aberto e de fotografias de trabalho no campo, aparecendo com seu enquadramento original (figura 3). O mesmo aconteceu na revista alemã $A I Z$, que saiu alguns dias depois da guerra ser deflagrada; aí ela aparece em um contexto bélico, mas ainda não sugerindo um ataque aéreo, já que apenas dez dias depois da insurreição militar ainda não se tinha idéia do papel fundamental que este tipo de ataque teria mais adiante no conflito (figura 4). Já em 1937 a fotografia reenquadrada foi publicada na capa do livreto de propaganda republicana Madrid, em uma montagem que trouxe aviões e uma bomba, colaborando com esta identificação da fotografia com a guerra (figura 5). Como o negativo original estava desaparecido, o simbolismo do bombardeio aderiu à imagem e nela permaneceu, aparecendo in- 
clusive em uma legenda equivocada de um livro de fotografias de Chim editado em 1974 pelo ICP - naquela época chamado de International Fund for Concerned Photography Inc., e hoje renomeado para International Center of Photography, a instituição que guarda seus arquivos - onde se lê "Air raid over Barcelona, 1938" (1974, p. 43).
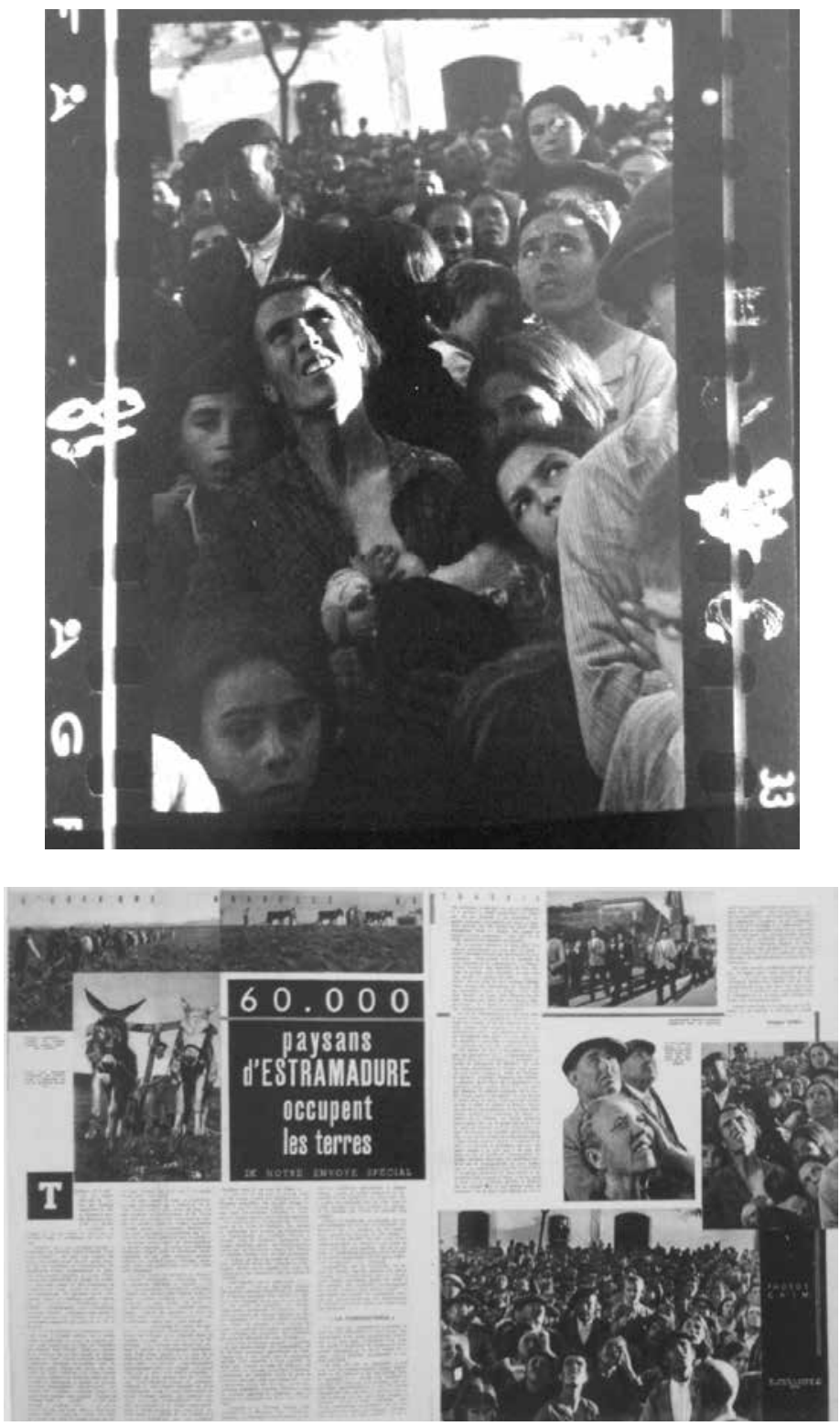

Figura 2

David Seymour "Chim". Mulher em reunião sobre divisão de terras. Estremadura, Espanha, abril ou maio de 1936 [a partir de negativo presente na Mala Mexicana]

Figura 3

Páginas da revista Regards de 14 de maio de 1936 
Figura 4

Páginas da revista AIZ de 29 de julho de 1936.

Figura 5

Capa do livreto Madrid, com fotomontagem a partir de fotografia de Chim, publicado na Espanha em 1937.
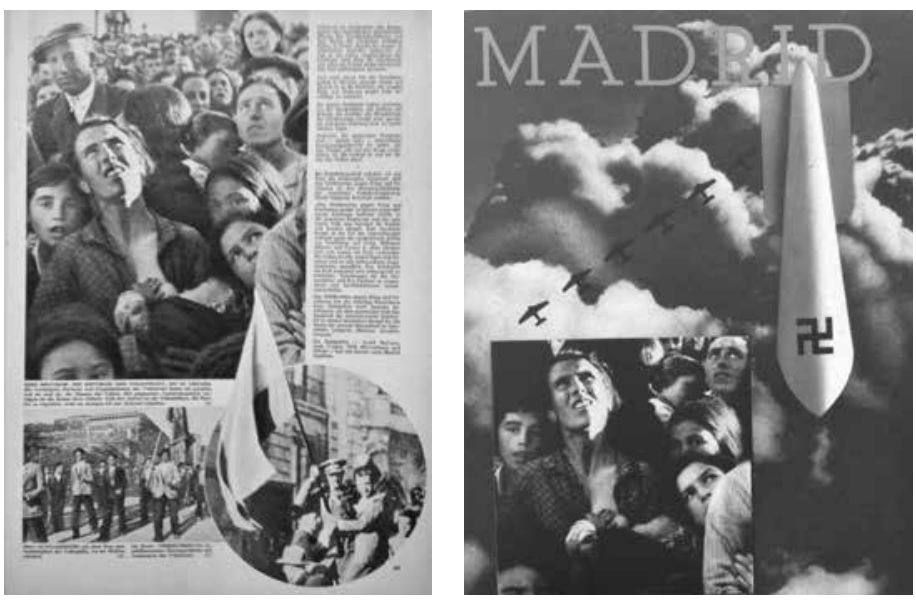

A grande polarização política entre esquerdas e o fascismo europeu, aliada à crença no valor de verdade e poder transformador da fotografia, levou à incorporação de alguns dos repórteres e fotógrafos no esforço de guerra, como foi o caso de Chim, que além de trabalhar para uma revista ligada diretamente ao PCF, também tinha uma posição pessoal de afinidade com a esquerda política. Assim, não há espanto na utilização da sua imagem reenquadrada para o livro de propaganda Madrid com significado diferente do original. Segundo Laurent Gervereau (2003, p. 218), os anos de 1930 foram um momento de construção de um imaginário político, e de uma utopia concretizada em imagens. As formas criadas pelo fascismo, pelo comunismo, pelo nazismo, eram então objeto de paixão, fé, esperança e mobilização. Assim, ainda segundo o autor, elas formariam um vocabulário de um tempo de crença laica - um vocabulário visual (GERVEREAU, 2003, p. 218). Podemos afirmar que a mãe que segura seu filho e olha para cima em desespero se tornou naqueles anos parte deste vocabulário, um verdadeiro topos visual para o sofrimento causado aos inocentes pela guerra.

O processo de apropriação pelo qual passou a fotografia de Chim ao chegar à capa de Madrid não foi uma exceção, fazia parte da prática comum da época de utilizar fotografias para fotomontagens de cunho político. Além de livros e revistas, a fotomontagem política era muito utilizada em cartazes. Assim que se pode identificar, por exemplo, o mesmo léxico ou vocabulário visual da madona moderna a que remete a fotografia feita em abril ou maio 1936 por Chim, em dois cartazes 

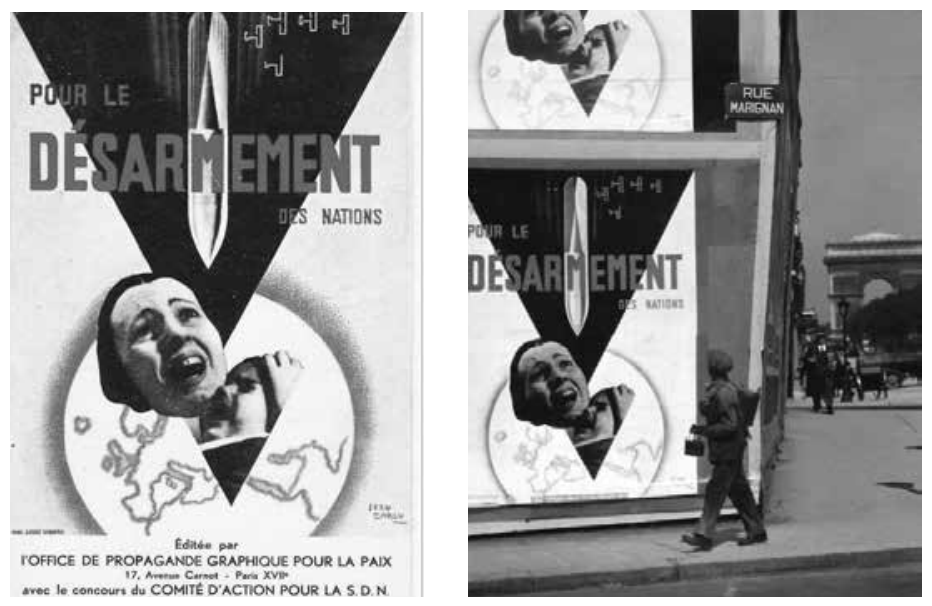

cujas fotografias passaram pelo mesmo processo. Na figura 6 se pode ver o cartaz de Jean Carlu, uma fotomontagem feita a partir de fotografia de André Vigneau. A fotografia foi feita especialmente para a montagem, e quem posou para ela foi a primeira esposa de Ernest Hemingway (GERVEREAU, 2003, p. 242). Semelhante à capa do livreto Madrid, com aviõezinhos que derrubam uma grande bomba, o cartaz era de cunho pacifista, e pedia desde 1932 "le désarmement des nations" nas ruas de Paris (figura 7).

Em agosto de 1936, então em um momento diferente, pois Hitler já era uma ameaça real para toda a Europa, e a guerra na Espanha já havia começado, Chim fotografou uma manifestação pela paz nos arredores de Paris. Em uma das fotografias, a figura 8, o cartaz de Carlu aparece no canto superior esquerdo.

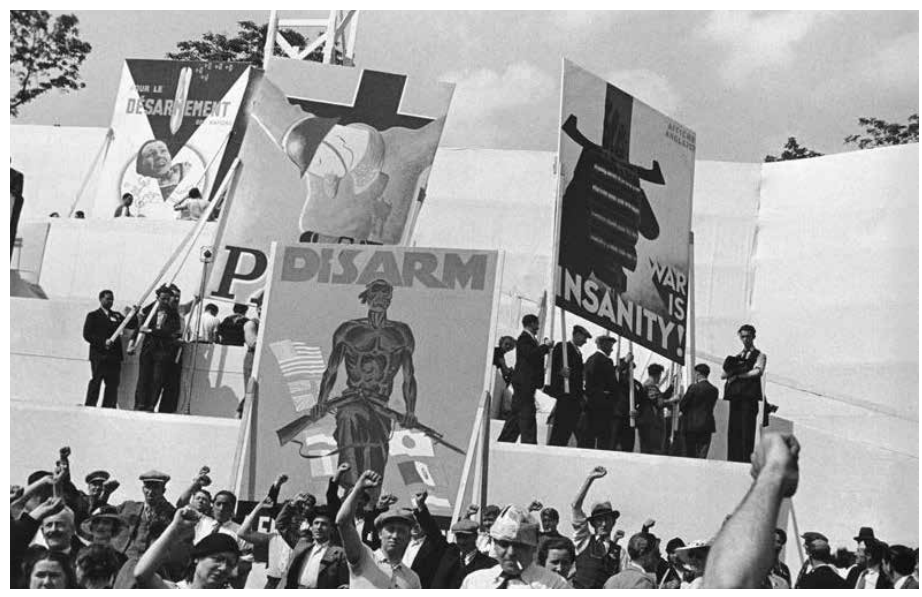

Figura 6

Jean Carlu. Cartaz com fotomontagem pacifista feita a partir de fotografia de André Vigneau.

França, 1932.

Figura 7

André Vigneau. Cartaz de Jean Carlu na Rue Marignan em Paris. França, 1932.
Figura 8

David Seymour "Chim". Manifestação pela paz em St. Cloud, nos arredores de Paris. França, 9 de agosto de 1936. 


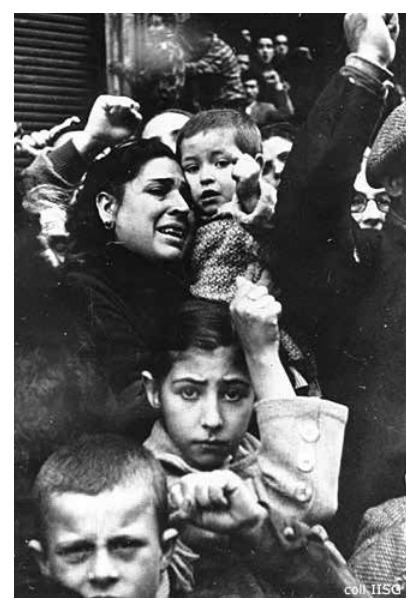

Figura 9

Autor desconhecido. Funeral de Buenaventura Durruti em Barcelona. Espanha, 22 de novembro de 1936.

Figura 10 Mariano Rawicz. Cartaz de propaganda, realizado com fotomontagem. Espanha, c. dezembro de 1936 ou janeiro de 1937.

Figura 11 David Seymour "Chim”. Passeata em memória dos mortos da Comuna no cemitério de Père Lachaise em Paris. França, 24 de maio de 1936.
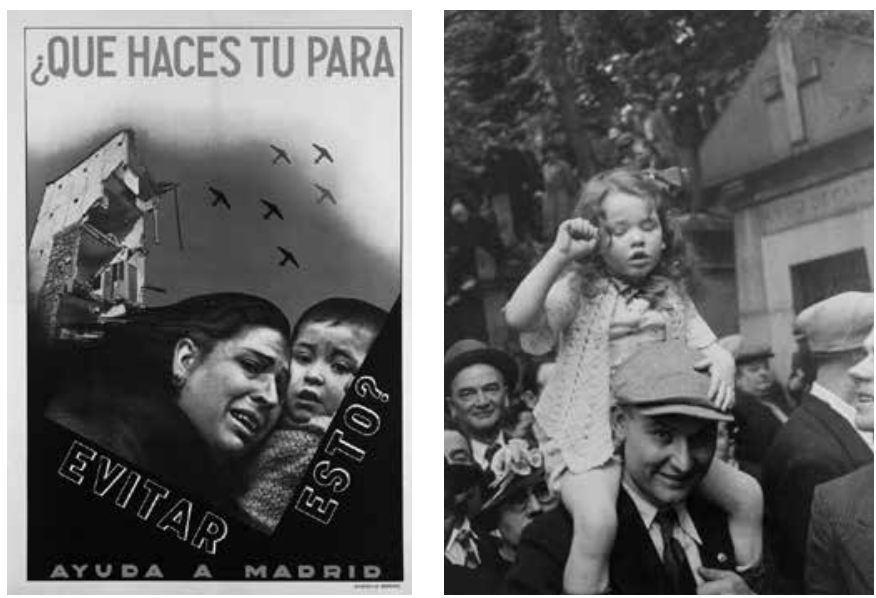

Entre o fim do ano de 1936, e no começo de 1937, um outro cartaz utilizando o mesmo vocabulário visual foi criado na Espanha em guerra por Mariano Rawicz. Ele foi bastante divulgado, ganhando versões em francês e em inglês dos dizeres "Que haces tu para evitar esto? Ayuda a Madrid", pois agora o momento de manifestar pacifismo havia passado e o engajamento contra a guerra pedia ações mais concretas (figura 10). Este cartaz traz os mesmo aviõezinhos que sobrevoam uma mãe desesperada segurando seu filho. Embora não tenha nenhuma figura de bomba, ao fundo há um prédio em ruínas, efeito lógico destas. A montagem foi realizada a partir de uma fotografia sem atribuição de autor ${ }^{3}$, que retrata esta mãe no meio de uma multidão durante o cortejo fúnebre do líder anarquista Buenaventura Durruti (figura 9). Portanto, assim como aconteceu com a fotografia de Chim, esta também ganhou um novo significado na fotomontagem. Na montagem, o pequeno braço da criança parece ter sido deliberadamente excluído da imagem para que não aparecesse o gesto que ele faz com o punho erguido, gesto característico da Frente Popular e do lado republicano da guerra. A montagem também retira todo o contexto espacial e a idéia da multidão presentes na fotografia original.

Estas três mães que estão com seus filhos ecoam de modo significativo um outro topos visual do período. Na França da Frente Popular, foram fotografadas de forma recorrente crianças carregadas nos ombros dos pais ${ }^{4}$, como se pode ver nas figuras 11 a 15. Todas estas fotografias mostram crianças, um pouco maiores do que as crianças que aparecem com as mães 

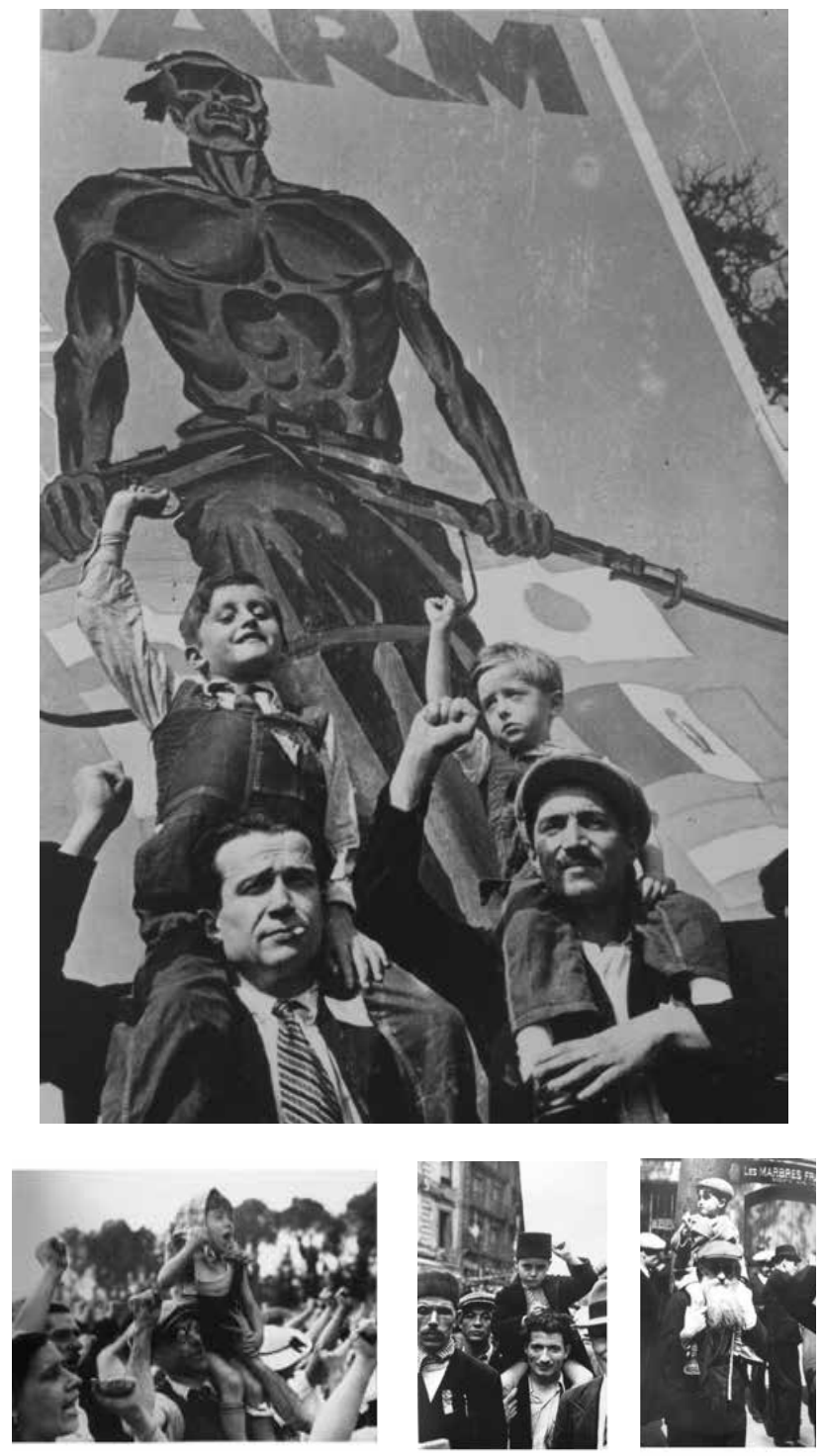

nas imagens anteriores, levadas nos ombros de homens que inferimos serem seus pais, no meio de multidões.

Diferente das multidões em que se encontravam as mães retratadas por Chim e pelo fotógrafo do cortejo de Durruti, estes pais não estão em meio a uma turba caótica, e nem foram retratados em momentos de desespero, mas durante manifestações políticas ligadas à Frente Popular. Assim, pode-se observar
Figura 12

David Seymour "Chim”. Manifestação pela paz em St. Cloud, nos arredores de Paris. França, 9 de agosto de 1936.

Figura 13

Autor desconhecido (agência Keystone). Cantando a Internacional, manifestação pela paz em Paris. França, 12 de junho de 1936.

\section{Figura 14}

Autor desconhecido (agência Roger-Viollet). Delegação de norte-africanos nas comemorações de 14 de julho em Paris. França, 1936.

\section{Figura 15}

Robert Capa. Celebração do $1^{\circ}$ de maio no Marais em Paris. França, 1937. 

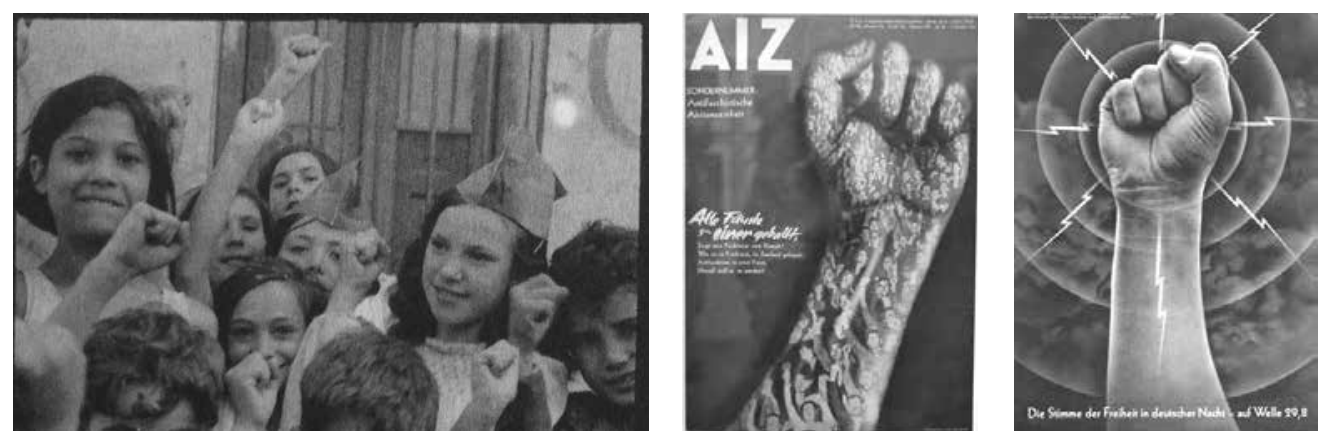

Figura 16 David Seymour “Chim". Crianças em Madri fazem a saudação republicana. Espanha, outubro de 1936.

Figura 17 John Heartfield. "Todos os punhos fechados em um”, capa da revista AIZ de 4 de outubro de 1934.

Figura 18 John Heartfield. "A voz da liberdade na noite alemã em comprimento de onda de 29.8", revista Vu de 21 de abril de 1937. que nestes dois casos as mães e suas crianças são retiradas de um espaço público, uma reunião de terras e um cortejo de líder político, para enfatizar um caráter de preocupação ou sofrimento. Deste modo, enquanto as mães, mulheres, são associadas à preocupação, ao cuidado com suas famílias frente à agressões - ou seja, um espaço privado, ainda que dentro de uma multidão - os pais são por outro lado associados à política e suas manifestações, e à alegria e esperança da construção de um mundo novo com suas famílias - e portanto parte de um espaço público.

As manifestações da Frente Popular Francesa não foram, no entanto, as únicas ocasiões em que Chim fotografou crianças fazendo a saudação dos punhos fechados. Também na Espanha durante a guerra este tema foi recorrente em suas fotografias, e Chim fotografou crianças espanholas fazendo esta saudação da Frente Popular em diversas situações, especialmente no período entre agosto e outubro de 1936. Uma das primeiras séries fotográficas que ele fez durante o conflito foi um registro demorado do cotidiano de crianças órfãs da guerra em uma creche ou orfanato em Madri, em agosto ou setembro de 1936. Estas crianças aparecem sentadas à mesa na hora da refeição, ou na sala de aula, mas sempre levantando os pequenos punhos fechados. Ele também as procurou não só nesta situação mais delicada, para onde foram mandadas provavelmente na condição de vítimas do conflito, mas também em situações de aglomeração de pessoas nas ruas em Talavera ou Madri, como mostra a figura 16. A opção nestes casos por buscar nas crianças os efeitos da guerra, assim como em uma situação de multidão voltar sua câmera para um enquadramento apenas de crianças, é significativo dentro do trabalho de Chim como um todo. Da mesma forma, em todos os casos as crianças estão alegres, que além de possivelmente ser uma tentativa 
de capturar o entusiasmo daquele momento, é também espelho do olhar e da estética de Chim, que naquele momento se constituía junto com a noção de fotografia humanista.

O gesto do punho fechado, que se tornou emblemático das Frentes Populares Alemã, Francesa e Espanhola, é uma das "formas" carregadas de ideais criadas por um movimento político, como chamou a atenção o trecho de Laurent Gervereau evocado mais acima (2003, p. 218). É também um dos aspectos da polarização política da sociedade européia entre as esquerdas e o fascismo, que predominou no entre-guerras. Neste sentido, o gesto dos punhos fechados ganhou força em contraposição ao gesto do braço estendido com a mão aberta usado pelos fascistas.

Como um exemplo do que Walter Benjamin chamou de estetização da política naquele momento (BENJAMIN, 1996, p. 196), a saudação do punho fechado foi uma "forma simbólica fixa” (VERGNON, 2005, p. 79) criada por John Heartfield, ativo colaborador da revista AIZ e membro do Partido Comunista Alemão (Kommunistische Partei Deutschlands, KPD), a partir de um desenho de Georges Grosz de 1922. O desenho, que se chamava Über den Gräben des März : Hütet euch! (sobre as sepulturas de março: tomem cuidado!), mostrava um homem sobre cruzes de um cemitério improvisado, levantando o braço com o punho fechado, em um gesto de cólera e desafio.

A partir de então Heartfield voltaria várias vezes para esta imagem do punho fechado, como, por exemplo, nas fotomontagens mostradas nas figuras 17 e 18 . Na primeira, o artista montou um grande braço com o punho fechado, que atravessa a capa da revista de cima a baixo e na diagonal da esquerda para a direita, formado por uma multidão de pessoas que fazem este gesto, deixando clara a mensagem de que a união - das esquerdas no caso - faria a força. Na segunda fotomontagem, um braço se ergue reto no centro da página, e seu punho fechado na parte superior funciona como uma antena de rádio, um meio de comunicação que estava ganhando muita força na época e que concorreu para a transformação da imprensa ilustrada no entre-guerras, e assim simboliza também um poder de agregação e de resistência.

Usando este mesmo topos, Heartfield criou em 1926 o símbolo da RFB (Rot-Front-Kämpferbunf), formação paramilitar do KPD. Já em 1924, um ano depois dos primeiros registros de Hitler e seus seguidores fazendo a saudação do braço estendido 
com a mão aberta, a RFB havia incluído em seu regimento a saudação com o punho fechado, seguida do grito Rot-Front!. Ainda na Alemanha, as duas saudações foram ganhando força durante a década de 1920: pelo lado comunista, durante as manifestações e campanhas eleitorais, especialmente em 1925, em que o candidato a presidente Ernst Thälmann apareceu em diversas ocasiões vestido como uniforme da RFB e fazendo o gesto do punho fechado; e pelo lado nazista, com sua transformação em norma do partido em 1926, vindo a se tornar célebre como manifestação das massas em imagens de multidões fazendo o gesto, como nos comícios de Nuremberg (VERGNON, 2005, pp. 79-81).

O gesto foi incorporado na França em 1926, através do PCF, no mesmo momento em que este criou seus "grupos de defesa anti-fascista". Foi a partir da década de 1930, no entanto, que ele se disseminou pelas massas. Assim, a partir de 1936, com a vitória nas eleições da Frente Popular, o gesto do punho fechado deixou de ter a conotação de desafio e ameaça e passou a ser um símbolo de agregação, de criação de uma identidade entre os membros e simpatizantes de esquerda. Deste modo, entre 1935 e 1939, este gesto serviu para afirmar uma comunhão de valores dos diversos partidos de esquerda membros da Frente Popular, valores estes estabelecidos em direta oposição àqueles do fascismo (VERGNON, 2005, p. 78).

Já na Espanha, o gesto apareceu incentivado por comunistas e socialistas em 1936 durante a campanha eleitoral que daria a vitória naquele mesmo ano para Frente Popular Espanhola. Após o levante militar que deu início à guerra civil em julho, e a explosão revolucionária que se seguiu, ele passou a ser usado pelas massas, porém com significado diferente do que para alemães ou franceses. Segundo Gilles Vergnon, levantar os punhos fechados na Espanha seria também um gesto de combate, mas não o de uma expressão coletiva, mas tranqüila de força, como no caso dos grevistas franceses, e nem de um ritual militar como no caso dos militantes alemães. Para este autor, o gesto quando usado pelos republicanos espanhóis, dentro do âmbito da luta entre fascistas e anti-fascistas, era um gesto de combate sem piedade, que mesmo após a derrota, permaneceu como gesto de desafio (VERGNON, 2005, p. 88).

Nos primeiros momentos da guerra na Espanha, no entanto, o gesto ainda não tinha essa conotação trágica que assumiria no decorrer do conflito, simbolizando apenas uma união, ou o desejo de união, internacional contra o fas- 
cismo. Assim, John Heartfield, já em 19 de agosto de 1936, portanto um mês exato depois do começo do conflito, publicou uma montagem em que ele associa uma fotografia realizada em Barcelona pelos fotógrafos Hans Namuth e Georg Reisner - comunistas alemães naquele momento exilados de seu país e também contratados da Regards - à famosa tela A liberdade guiando o povo, de Delacroix, tão simbólica e representativa do passado revolucionário dos franceses (figuras 19 e 20). O miliciano sem camisa que ergue uma bandeira saudando os soldados que partem para a frente de batalha foi então associado à figura da liberdade, que guia $o$ povo francês na famosa pintura.

A carga revolucionária do gesto do punho fechado, presente em sua origem alemã, mas aos poucos minimizada com as coalizões das diferentes ideologias de esquerda nas frentes populares, voltou assim com toda a sua força na montagem de Heartfield. Com o decorrer do conflito a República Espanhola viria a negar o caráter revolucionário da guerra, afirmando que apenas se defendia de um golpe fascista, mas naquele momento a fotografia de Namuth e Reisner e a montagem de Heartfield não deixam dúvidas de que a guerra estava sendo vista sim por muitos membros das esquerdas como uma revolução, que deveria portanto ser retratada com a tradição imagética deste tipo de evento. Naqueles primeiros meses da guerra espanhola anteriores à assinatura do Pacto de Não-Intervenção, ainda havia um entusiasmo advindo dos sucessos localizados na contenção do levante militar - os mesmos sucessos que permitiram a Namuth, Reisner e Heartfield ver o evento pelo prisma revolucionário - e a esperança de que as outras democracias se unissem em uma frente internacional contra
Figura 19

Página da revista alemã editada em Praga Die Volks Illustrierte de 19 de agosto de 1936, com fotomontagem de John Heartfield .

Figura 20

Hans Namuth e Georg Reisner. Partida de milicianos republicanos para a frente de batalha em Barcelona. Espanha, julho de 1936.
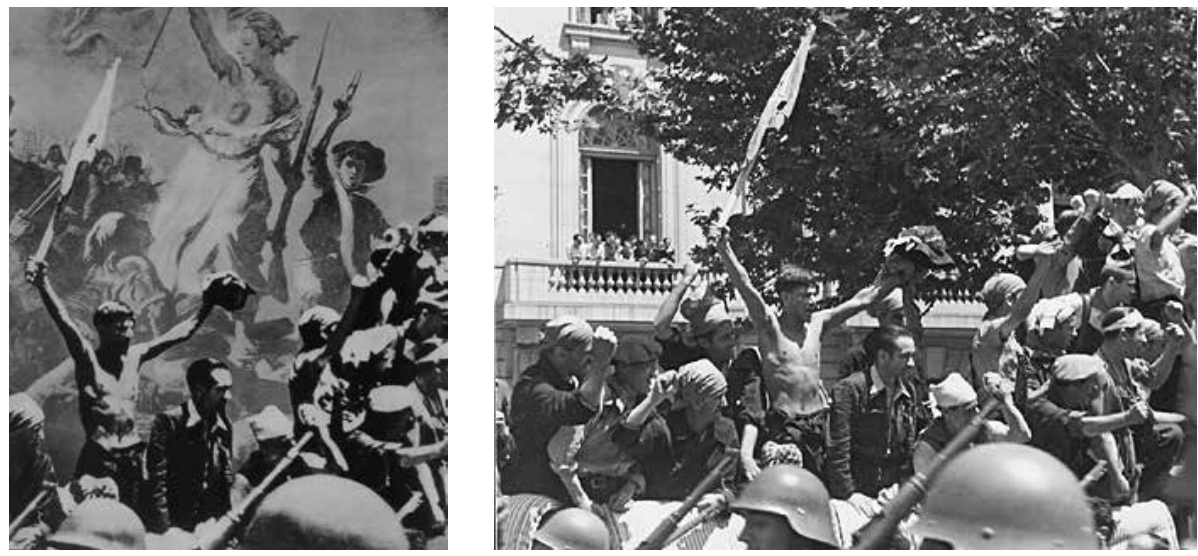
o fascismo. Ao mesmo tempo, ao aproximar a luta do povo francês de um século antes à causa espanhola, a montagem de Heartfield sugeria uma proximidade entre os dois países que levasse a França a apoiar a Espanha republicana.

Ao retratar crianças espanholas fazendo o mesmo gesto que as crianças com seus pais nas comemorações e reuniões populares da esquerda francesa, Chim também operou esta proximidade, que parece buscar igualmente uma maior empatia dos franceses com a causa espanhola. Esta presença reiterada, portanto, de crianças fazendo a saudação da Frente Popular nas fotografias de Chim nos três primeiros meses da guerra civil não é aleatória, mas significativa, pois fala sobre os acontecimentos políticos tumultuosos do período. A política de união das esquerdas em Frentes Populares havia fracassado na Alemanha em 1933, com a vitória do partido nazista e a subida de Hitler a chanceler. Ela havia, no entanto, saído vitoriosa na Espanha, em 16 de fevereiro de 1936, e em seguida na França, em 3 de maio daquele mesmo ano. Quando ela foi ameaçada pelo golpe militar de Franco, a Frente Popular Francesa passou a ficar não só isolada, mas também ameaçada (SERRANO, 1987, pp. 37-38). Assim, com os temores de que a guerra se espalhasse para o resto da Europa, o governo francês votou a favor de um tratado de não intervenção para a guerra da Espanha já em 7 de agosto. Ineficaz na contenção da ajuda alemã e italiana para os nacionalistas liderados pelo General Franco, a assinatura do tratado causou distúrbios para a coalizão dos partidos da Frente Popular Francesa. O PCF protestou, e a imprensa comunista se esforçou em fazer propaganda contra esta não intervenção, ambos sem sucesso. Quando a União Soviética anunciou, em 23 de outubro de 1936, que não iria respeitar o pacto que era tão acintosamente desrespeitado pelos aliados fascistas, o PCF iniciou um racha dentro do governo francês que iria apenas aumentar até culminar com a renúncia do presidente Léon Blum em 21 de junho de 1937 (HOBSBAWM, 2007, pp. 160-161).

Antes disso, porém, naqueles três primeiros meses da guerra espanhola, entre agosto e outubro de 1936, ainda havia um entusiasmo revolucionário advindo dos sucessos localizados na contenção do levante militar, e a esperança de que as outras democracias se unissem em uma frente internacional contra o fascismo. Daí uma iconologia de esquerda, ao mesmo tempo humanista e simbólica, utilizada por 
Chim, que, empregado por uma revista francesa ligada ao Partido Comunista, não poderia deixar de ver o conflito espanhol por este viés. Olhar que conforme o entusiasmo e as esperanças republicanas foram arrefecendo, daria também lugar a outro tipo de registro fotográfico.

\section{NOTAS}

1. A Regards se auto-intitulava "a revista ilustrada da Frente Popular" (BROTHERS, 1997, pp. 4-6).

2. Falando sobre esta imagem, Susan Sontag (2003, p. 28) observou: "Normalmente, se existe alguma distância com relação ao tema, aquilo que uma foto 'diz' pode ser lido de diversas maneiras. Cedo ou tarde, lê-se na foto aquilo que ela deveria estar dizendo".

3. A imagem está hoje no Arxiu Nacoinal de Catalunya. Muito provavelmente ela fazia parte dos esforços de registro fotográfico e de propaganda realizados pelo Comissariat de Propaganda da Generalitat catalã, comandado pelo jornalista e fotógrafo Jaume Miravitlles. O fotógrafo de vanguarda Pere Català Pic cuidava da parte de fotografia, tendo muito provavelmente parte na concepção ou autoria de fotomontagens como as do livreto Madrid (VILLARROYA et. al., 2006, pp. 18-65).

4. Esta temática seria retomada nas fotografias de maio de 68 (DENOYELLE et al, 2006, p. 84).

\section{Referências}

BROTHERS, Caroline. War And Photography: A Cultural History. London, New York: Routledge, 1997.

BAQUÉ, Dominique (ed). Les Documents de la Modernité, anthologie de texts sur la photographie de 1919 a 1939. Nîmes: Jacqueline Chambon, 1993.

BENJAMIN, Walter. Obras Escolhidas. Magia e técnica, arte e política. São Paulo: Brasiliense, 1996.

DENOYELLE, Françoise, et al., Le Front Populaire des Photographes. Dijon: Éditions Terre Bleue, 2006.

FONTAINE, François. La Guerre d'Espagne, un déluge de feu e d'images. Paris: Berg International Éditeurs, 2003.

GERVEREAU, Laurent. Histoire du Visuel au XXe Siècle. Paris: Seuil, 2003.

HOBSBAWM, Eric. Era dos Extremos, $O$ breve século $X X$, 1914-1991. São Paulo: Cia das Letras, 2007.

MOREL, Gaëlle. Du People au Populisme. Les couvertures du magazine communiste Regards. Études Photographiques n9, mai 2001, pp. 44-63.

. La modernité des couvertures du magazine communiste Regards (1932-1936): La photographie de pro- 
pagande antifasciste. Mémoire de maîtrise d'histoire de l'art, Université Paris I, 1999.

. L'expression d'une crise d'identité: La photographie humaniste dans les couvertures du magazine communiste Regards (1937-1939 et 1945-1947). Mémoire de DEA d'histoire de l'art, Université Paris I, 2000.

NAGGAR, Carole (ed). David Seymour. Col. Photo Poche 138. Paris: Actes Sud, 2011.

SERRANO, Carlos. L'Enjeu Espagnol. PCF et guerre d'Espagne. Paris: Messidor, 1987.

SONTAG, Susan. Diante da Dor dos Outros. São Paulo: Cia das Letras, 2003.

VERGNON, Gilles. Le "poing levé ", du rite soldatique au rite de masse. Jalons pour l'histoire d'un rite politique. Le Mouvement social, n. 212 (jul.-sep., 2005), pp. 77-91.

VILLARROYA, Joan et. al. Guerra i Propaganda. Fotografies del Comissariat de Propaganda de la Generalitat de Catalunya (1936-1939). Barcelona / Sant Cugat del Vallès: Viena Edicions / Arxiu Nacional de Catalunya, 2006.

YOUNG, Cynthia (ed). The Mexican Suitcase. New York, Gotingen: International Center of Photography, Steidl, 2010, 2 vols.

Recebido em: 31/03/14

Aceito em: 31/07/14 


\section{ERIKA ZERWES \\ erikazerwes@gmail.com}

Doutora em História (2013) com a tese Tempo de Guerra - Cultura visual e cultura política nas fotografias de guerra dos fundadores da agência Magnum, 1936-1947. Mestre em História (2008) com a dissertação A Fotografia Eloqüente: Arte e política em Aleksandr Rodchenko, 1924-1930. Ambos pelo Instituto de Filosofia e Ciências Humandas da Universidade de Campinas e sob orientação da profa. dra. Iara Lis Schiavinatto. Graduada em Filosofia pela Faculdade de Filosofia, Letras e Ciências Humanas da Universidade de Sâo Paulo (2004). 